\title{
ARTIGOS
}

\section{Avaliação do efeito protetor e curativo da Punica granatum Lin. no processo de cicatrização tecidual em queimaduras induzidas em mucosas de ratos}

\author{
Evaluation of the protective and curative effect of Punica \\ granatum Lin. in the process of tissue healing in burns induced \\ in mucous membranes of rats
}

\begin{abstract}
RESUMO
O objetivo deste estudo foi avaliar o efeito protetor e curativo no processo de cicatrização tecidual, da ingestão do suco da polpa e da ação local do chá do fruto da Punica granatum L; em queimaduras induzidas em dorso da língua de ratos. Metodologia: Trata-se de um estudo prospectivo e experimental, realizado em 48 ratos machos Wistar, idade entre 60 a 65 dias e peso médio $275 \mathrm{~g}$. A amostra foi dividida em 02 grupos A e B, onde o A avaliava o efeito protetor da Punica granatum e B seu efeito curativo após queimadura. Cada grupo foi subdividido em 04 subgrupos e receberam os seguintes tratamentos (A1 água destilada), (B1 controle), (A2 e B2: chá em forma tópica), (A3 e B3: chá tópico e suco via gavagem) e (A4 e B4: suco via gavagem). Durante o experimento, foi realizada análise clinica da contração da ferida no $7^{\circ}$. e $14^{\circ}$ dias após a indução da lesão, nos subgrupos dos grupos A e B. Resultados: Todos os subgrupos apresentaram contração da ferida, sendo que no $7^{\circ}$ dia o subgrupo A2 obteve contração mais intensa e no $14^{\circ}$ a contração mais intensa da ferida foi observada nos subgrupos A2 e B2. Conclusão: Os tratamentos protetor e curativo com chá (A2/B2) apresentaram clinicamente e estatisticamente uma média percentual de contração da ferida superior a todos os outros tratamentos.

Palavras- chave: Punicaceae, Cicatrização, Mucosa Bucal.
\end{abstract}

\section{ABSTRACT}

Evaluation of protective effect of Punica granatum Lin and curative. in the process of tissue, healing in Burns induced in mucous membranes of rats. The objective of this study was to evaluate the protective and curative effect in tissue healing process, the intake of pulp and juice of fruit tea action of Punica granatum $L$; in Burns induced in rat tongue dorsum. Methodology: this is a prospective study and experimental, 48 Wistar male rats performed at, between the ages of 60 to 65 days and average weight $275 \mathrm{~g}$. The sample was divided into A and B groups 02 , where the assessed the protective effect of Punica granatum and B your curative effect after burn. Each group was subdivided into subgroups 04 and received the following treatments (A1 distilled water), (B1), (A2 and B2: tea in topical form), (A3 and B3: tea and juice topic via gavage) and (A4 and B4: juice via gavage). During the experiment, clinical analysis of wound contraction at $7^{\circ}$ and $14^{\circ}$ days after induction of injury in subgroups of groups A and b. Results: all the subgroups presented wound contraction, and in 7 th day the subgroup A2 obtained more intense contraction in $14^{\circ}$ the more intense the wound contraction was observed in subgroups A2 and B2. Conclusion: The protective and curative treatments with tea (A2/B2) showed clinically and statistically average percentage of wound contraction superior to all other treatments.

Keywords: Punicaceae, Wound Healing, Mouth Mucosa.

\section{João Epaminondas Silva de Araújo* Ericlene Farias de Oliveira** Leonardo Magalhães Carlan*** Fernanda Bastos Martins**** Maria de Lourdes da Silva Arruda Morais*****}

* Graduado em odontologia pela Universidade Potiguar, Bolsista PIBIC (Programa de iniciação cientifica do Hospital da Liga Norte Riograndense Contra o Câncer (HLNRCC)). epaminondaslopes@gmail.com

Endereço para correspondência: Av. Miguel Castro, n¹355, Dix-Sept Rosado-Natal/RN, CEP: 59075-740

** Graduado em Odontologia pela Universidade Potiguar, Bolsista PIBIC (Programa de iniciação cientifica do Hospital da Liga Norte Riograndense Contra o Câncer (HLNRCC)) - ericlenefarias7@gmail.com

*** Graduado em Odontologia pela Universidade Potiguar-leo_thrix@hotmail.com

**** Estudante de graduação em odontologia pela Universidade Potiguar - fernandabastos620@gmail.com

***** Doutora em Ciências da Saúde, Profa Adj IV da Universidade Potiguar, Profa Adj IV da Universidade do Estado do Rio Grande do Norte e Pesquisadora do HLNRCC.: lourd_arruda@hotmail.com 


\section{INTRODUÇÃO}

O conhecimento sobre a aplicação de partes de plantas para fins medicinais na saúde humana primária são resultados de experiências práticas, observações e rituais sócios religiosos milenares, passados através de gerações ${ }^{1}$. A escolha de plantas empregadas na saúde humana ocorre inicialmente pelos achados etinobotânicos. No entanto, a seleção ideal deve ser baseada em extensos e desafiadores estudos sobre a sua evolução fitoquímica ${ }^{2-3}$.

Dentre os alimentos fontes de compostos bioativos, pode-se destacar a romã (Punica granatum L.), uma das frutas mais tradicionalmente consumidas. Nos últimos anos, tem aumentado o interesse científico por esta fruta devido aos seus benefícios produzidos à saúde humana, conforme a literatura ${ }^{4}$.

As propriedades fitoquímicas da romã são avaliadas em estudo no mundo todo, por meio dos extratos de partes frescas e desidratadas de toda a planta, devido ao potencial antioxidante in $\mathrm{vivo}^{5}$, atividade antibacteriana, antifúngica e antinflamatório ${ }^{6}$, antimalarial ${ }^{7}$, antitumoral e antimutagênico ${ }^{8}$.

Estas propriedades terapêuticas são atribuídas aos compostos fenólicos, substâncias que ocorrem da raiz às folhas da planta para protegê-la do estresse ambiental ${ }^{9}$. A casca da romã corresponde a cerca de $50 \%$ do peso total da fruta e é uma importante fonte de compostos bioativos como ácido elágico e seus derivados e elagitaninos como punicalina e punicalagina ${ }^{4}$. A casca do fruto possui atividade antioxidante, rica em flavonoides e taninos ${ }^{10}$. Estes polifenóis presentes na casca podem ser responsáveis pela atividade de cicatrização de feridas ${ }^{11-12}$.

No estudo de Husari ${ }^{13}$ (2014), o suco de romã reduziu significativamente o estresse oxidativo, reduziu a inflamação, o edema e a infiltração de neutrófilos em hiperóxia. As $\alpha$ punicalaginas e monômeros $\beta$ são os elagitaninos responsáveis pelas propriedades do suco de romã7.

Na literatura todas as formas de tratamento utilizando romã, são voltadas para o alívio dos sintomas e cicatrização das úlceras. Os medicamentos usados reduzem a dor e a frequência de aparecimento das lesões. De tal modo os tratamentos com romã podem ser administrados de forma tópica ou sistêmica, através do uso de medicamentos alopáticos, homeopáticos ou produtos naturais, além das formas alternativas de tratamento como a aplicação do laser de baixa potência ${ }^{14-16}$.

A importância de estudos com a romã (Punica granatum L.) é ratificada pelo fato de que os agentes fitoterápicos produzem menos agressões ao organismo, apresentando-se como terapia alternativa frente aos microrganismos resistentes ao tratamento com medicamentos alopáticos ${ }^{17}$.

Diante do exposto, o presente estudo tem como objetivo avaliar o efeito protetor e curativo da Punica granatum L. no processo de cicatrização tecidual em queimaduras induzidas em mucosas de ratos.

\section{MATERIAIS E MÉTODOS}

Trata-se de um estudo prospectivo e experimental aprovado pelo comitê de ética no uso de animais (CEUA) com parecer de número 001/2017, onde foi avaliada a eficácia 
da romã na proteção da mucosa e na cicatrização das feridas pós-queimaduras em região posterior e mediana do dorso da língua de ratos. Para tanto, a amostra foi composta por 48 animais, os quais foram divididos em 02 grandes grupos A e B, onde o grupo A avaliava o efeito protetor da Punica granatum e B o efeito curativo da Punica granatum após queimadura. Cada grupo foi subdividido em 04 subgrupos, contendo 06 ratos cada, os quais receberam os seguintes tratamentos (A1 água destilada), (B1 não utilizou nada), (A2 e B2: chá aplicado localmente), (A3 e B3: chá local e suco via gavagem) e (A4 e B4: suco via gavagem).

Para a avaliação da eficácia da romã na proteção da mucosa oral de ratos, o grupo A, utilizou água destilada (uso local e gavagem), chá (uso local) e suco (uso por gavagem) teve inicio 07 dias antes da realização da ferida e continuou até 14 dias após. Já para a avaliação do efeito curativo, o grupo B, teve a aplicação destas substancias só após a realização da ferida e continuou por 14 por dias. Em ambos os grupo, a utilização das substancias previamente citadas, foram administradas 02 vezes ao dia.

Foram incluídos na pesquisa ratos norvegicus, linhagem Wistar variação albinus, idade entre 60 a 65 dias e peso entre 250 a $300 \mathrm{~g}$ do sexo masculino e que não apresentavam nenhuma patologia clinica visível, sendo excluídos os animais que não atenderam aos critérios de inclusão. Esses animais foram pesados e distribuídos de forma aleatória em gaiolas individuais, preparadas com cama de maravalha, mantidos 12 horas sobre luminosidade e seguida por 12 horas de ambiente escuro, com temperatura controlada por meio de ar-condicionado variando na faixa de 22 a $23^{\circ}$ e alimentação comercial normal. A comida e a água foram fornecidas à vontade.

O material vegetal da romã (Punica granatum L.) foi adquirido em Mercado local, sendo classificada e catalogada como Punica granatum Linn por biólogo da Universidade Potiguar - RN. Para o Preparo das amostras, os frutos foram lavados em água corrente com o auxilio de uma escova, secos com papel toalha, em seguida abertos em frações de 6 a 8 pedaços. Na obtenção do chá, as partes do fruto foram secas em estufa a $55^{\circ} \mathrm{C}$ durante 7 dias, em seguida triturado e armazenado em saco plástico, mantido a $7^{\circ} \mathrm{C}$ até o momento das aplicações. Posteriormente foi preparado em forma de chá, sendo utilizado 5 e $10 \mathrm{~g}$ da parte seca em 10 e $20 \mathrm{ml}$ de água destilada, fervido por 1 minuto, de acordo com o método descrito por Teles \& Costa $^{18}$ (2014). Em seguida, o mesmo foi coado em papel filtro, e a sua utilização se deu em temperatura ambiente. Para o preparo do suco, a casca foi separada da polpa, sendo a polpa prensada e em seguida coada e o suco disponibilizado para o fornecimento. Uma análise fitoquímica das amostras do suco da polpa e do chá do fruto desidratado da púnica granatum foi realizada para a determinação de seus constituintes, de acordo com método descrito por Bhandary ${ }^{19}$ (2012).

Durante a administração destas substâncias, de acordo com o subgrupo, o suco da polpa da romã foi administrado por gavagem, duas vezes ao dia, na dosagem de 300 $\mathrm{mg} / \mathrm{Kg}$, em volume de $3 \mathrm{ml}$ de acordo com o método descrito por Mohan ${ }^{20}$ et al.(2010). O chá do fruto foi aplicado com uma seringa descartável, por gotejamento, 0,5 a 0,6 ml (1g/ $\mathrm{Kg}$ ) sobre a queimadura, duas vezes ao dia. A água destilada utilizada para o grupo controle A1, foi feita pela técnica de gavagem e por gotejamento, O grupo B1 não recebeu nenhum tratamento.

Para a realização da queimadura no dorso da língua dos animais, os mesmos foram anestesiados com solução anestésica de zooletil@ $50^{\circ}$ anestésico injetável composto por 
cloridrato tiletamina e cloridrato zolazepam na proporção de 1:1, por via intramuscular na região de quadrícepes, na dose de $50 \mathrm{mg} / \mathrm{kg}$ com seringas descartáveis de $1 \mathrm{ml}$ e agulha 0,45 x $1326 \mathrm{G}$ 1⁄2 Descarpack. A ação anestésica foi verificada pela ausência do reflexo de retirada da pata ao estímulo doloroso. Após este procedimento, realizou-se a queimadura na parte posterior do dorso da língua dos animais, com brunidor de amalgama número 29 de uso odontológico, aquecido até atingir cor rubra, em um bico de Bunsen, encostando-se à mucosa do dorso da língua do animal, por 1 segundo, de acordo com a metodologia descrita por Nascimento Junior et al. ${ }^{21}$ (2016). Na ocasião, utilizou-se a extremidade do cabo, com diâmetro circular de 5,10 mm em uma profundidade de $1 \mathrm{~mm}$. A lesão foi realizada em todos os anim ais por um único pesquisador.

Uma vez induzidas as queimaduras, foram feitas as administrações das substâncias de acordo o protocolo estabelecido acima. É importante ressaltar que os subgrupos A, iniciaram o uso das substancias sete dias antes da realização da queimadura, continuando a recebê-las por mais 14 dias. Os subgrupos B, que avaliaram o efeito cicatrizante da romã (Punica granatum L.), iniciaram a administração dos fitoterápicos imediatamente após a realização da queimadura por um período de 14 dias.

O processo de contenção diária para a administração das substâncias, seja por gavagem ou aplicação tópica local, foi o método de contenção parcial realizado pelos pesquisadores, dispensando o uso de qualquer tipo de anestésico, ou substância que viesse deprimir o sistema nervoso central do animal.

A avaliação clínica da ferida foi realizada no primeiro dia do experimento, imediatamente após a queimadura no dorso da língua dos ratos, sendo feito a aferição de seu tamanho com o paquímetro digital, registradas com câmera fotográfica, sendo repetida após 07 e 14 dias em todos os animais, por um único pesquisador à cega com relação ao tipo de tratamento recebido pelo animal, com o objetivo de não haver influência nos resultados. Os dados foram anotados em fichas previamente elaboradas. A análise de aferição clínica do tamanho da ferida, foi realizada nos sentidos: anterior-posterior e latero-lateral, de acordo com método proposto por Teo \& Naylor ${ }^{22}$ (1995), onde: Ai - Af / Ai x 100 (sendo: Ai - Área inicial da ferida, Af - Área final da ferida).

Os dados obtidos foram analisados estatisticamente através do teste ANOVA (analise of variance) e Turkey.

\section{RESULTADOS}

$\mathrm{Na}$ analise qualitativa do suco da polpa foram encontrados os seguintes fitoconstituintes: flavonoides e taninos. O chá do fruto desidratado da Punica granatum L. apresentou-se os seguintes componentes: Alcaloides; Flavonoides; Taninos; Proteínas; Aminoácidos e Carboidratos. 
QUADRO 1. Fitoconstituintes encontrados nas amostras do suco da polpa e do chá do fruto desidratado da romã (Punica granatum $L$ ).

\begin{tabular}{|c|c|c|c|c|c|c|c|c|}
\hline \multicolumn{9}{|c|}{ Fitoconstituintes } \\
\hline Análise das amostras & 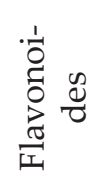 & $\begin{array}{l}\frac{0}{0} \\
\frac{0}{0} \\
\frac{\pi}{0} \\
\frac{0}{4}\end{array}$ & 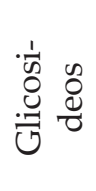 & 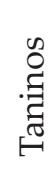 & 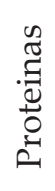 & 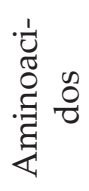 & 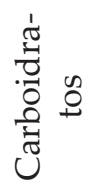 & 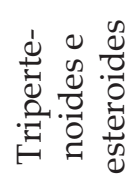 \\
\hline Suco & + & - & - & + & - & - & - & - \\
\hline Chá & + & + & - & + & + & + & + & - \\
\hline
\end{tabular}

(+) presente (-) ausente

Após a determinação dos constituintes do suco e do chá, deu início ao experimento desta pesquisa, com amostra inicial de 48 animais, havendo a redução para 47 devido ao óbito de um animal no dia seguinte à indução da queimadura. Todos os animais apresentaram perda de peso nos 07 primeiros dias após a indução do trauma, porém aos 14 dias apenas o subgrupo A1 continuou com perda progressiva de sua massa corpórea.

Todos os animais apresentaram mudanças na aparência física com relação à postura, textura do pelo e mudanças no comportamento normal como inatividade, sendo estes presentes apenas aos 07 primeiros dias após a indução da queimadura.

FIGURA 1: Metodologia utilizada para realização da queimadura e aplicação dos fitoterápicos. (A) Realização da queimadura utilizando instrumental de origem odontológica, (B) Mensuração da lesão com a utilização de paquímetro digital, (C) Aplicação do chá pelo método de decocção sobre a lesão, (D) Aplicação do suco via gavagem nos animais.
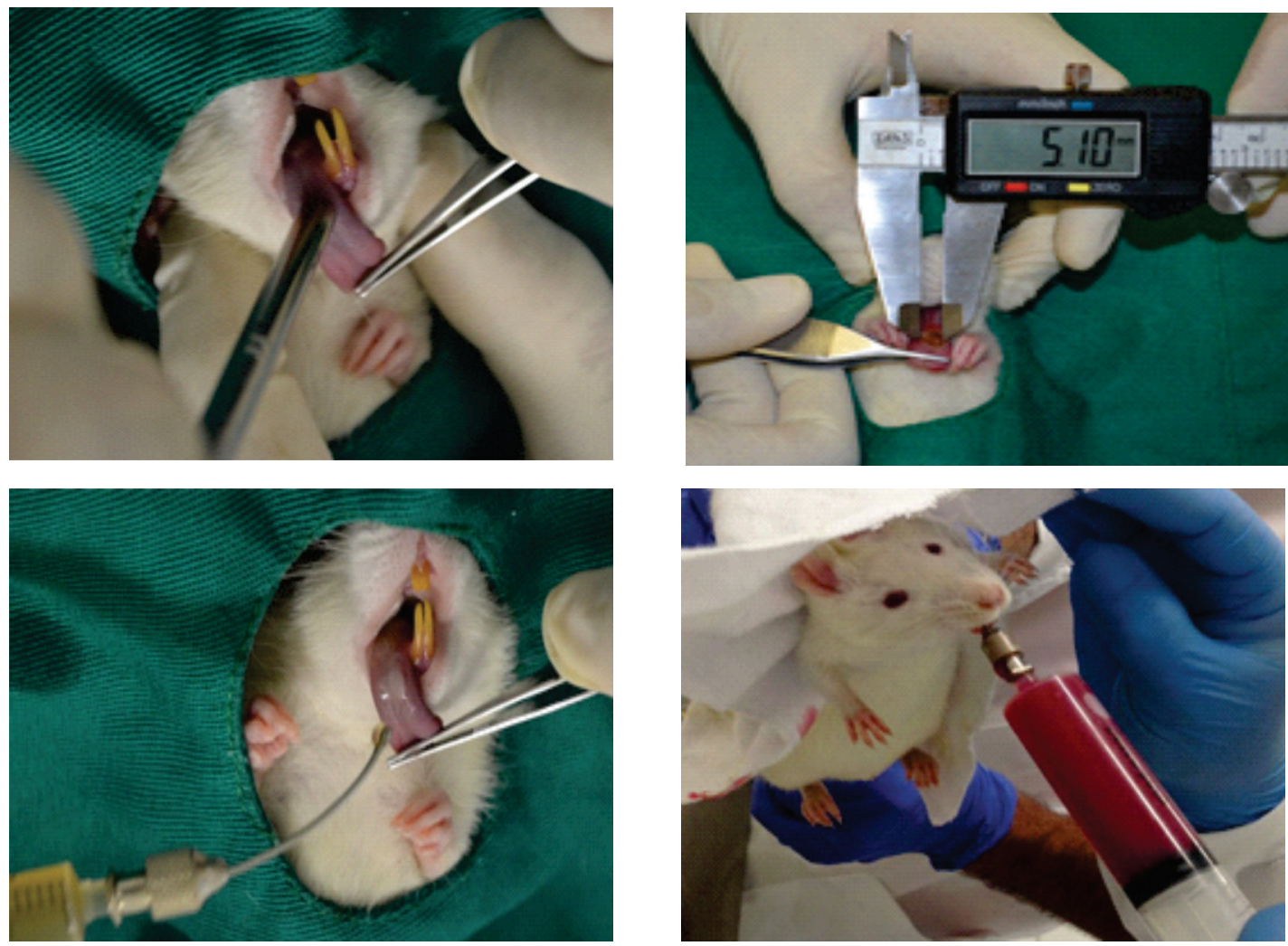
No que diz respeito a analise clínica para avaliação da contração da ferida, após 07 e 14 dias dos grupos protetor (Grupo A) e curativo (Grupo B), pode-se observa que aos 07dias quando realizada a comparação dos achados encontrados em todos os subgrupos A (Protetor) e B (curativo), observou-se clinicamente que a contração da ferida do subgrupo A2 (Chá) foi a mais intensa para ambos os grupos, apresentando percentual de 52,98\% e 43,58\% de contração da ferida, para os subgrupos A2 e B2 respectivamente. Considerando-se os 14 dias após a indução da ferida, os subgrupos A2 e B2 continuam a apresentar um melhor percentual de contração, havendo porém uma aproximação nos valores apresentados pelo mesmo, $80,93 \%$ e $78,50 \%$, respectivamente.

GRÁFICO 1. Percentual de contração da ferida em todos os subgrupos aos 07 e 14 dias, neste estudo.

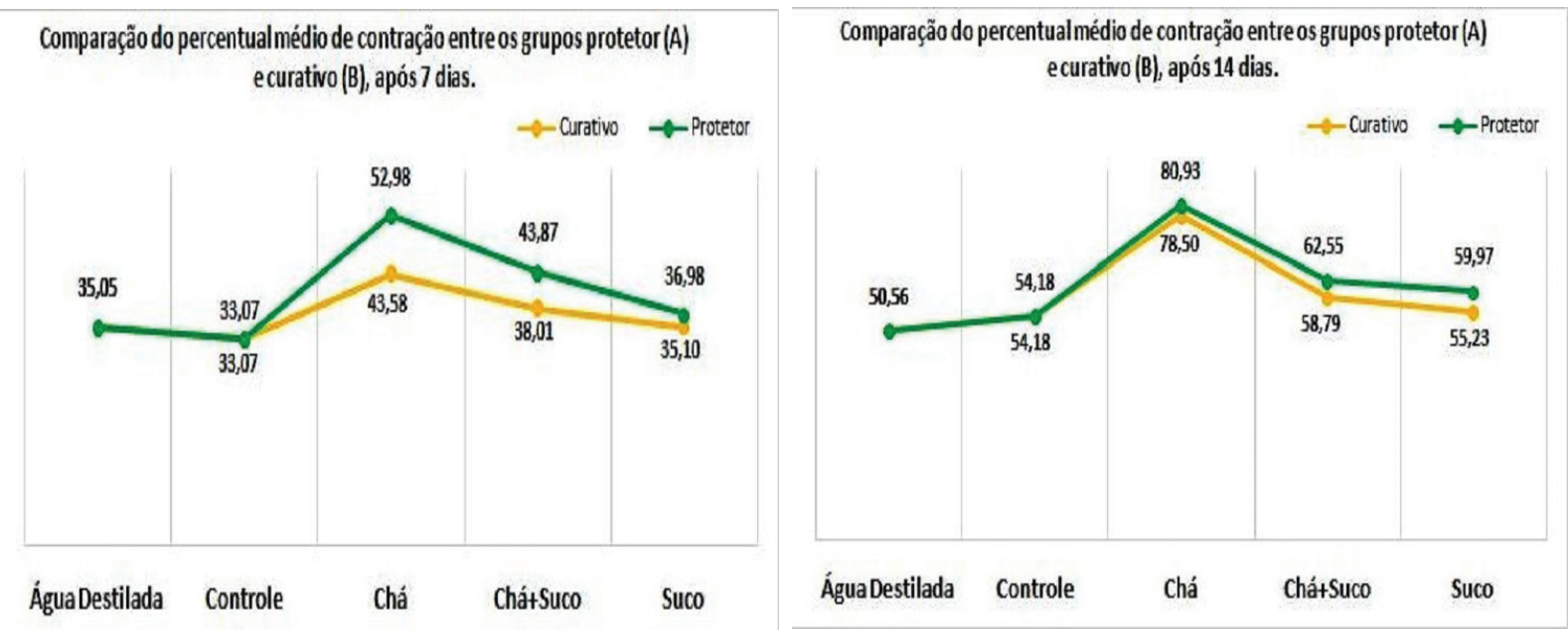

Todas as médias supracitadas foram submetidas ao teste ANOVA (analise of variance), com nível de significância de 5\%, no qual o valor de P, quando significativo, foi aplicado o teste de Tukey para a confirmação dos dados.

Quando calculamos ANOVA considerando os dois grupos (Protetor (A) e Curativo (B)) após 7 dias de indução, o valor-p encontrado foi de 0,4038, ou seja, ao nível de significância de 5\%, o teste considerou que não houve diferença entre as médias de contração da ferida entre os subgrupos.

A ANOVA também foi aplicada para avaliar os achados aos 14 dias após a indução da ferida nos dois grupos, Protetor (Grupo A) e Curativo (Grupo B), onde foi encontrado um valor-p $(<0,0001)$ significativo, ou seja, com o nível de significância de $5 \%$, o teste considerou que existe diferença entre as médias de contração da ferida entre os subgrupos. Para verificar quais das médias dos subgrupos apresentam um melhor percentual de contração da ferida, o teste de Tukey foi aplicado, os resultados estão apresentados no quadro 2 a seguir:

QUADRO 2. Resultados significativos do teste Tukey comparando o grupo Protetor (grupo A) e Curativo (grupo B), após 14 dias de indução. 


\begin{tabular}{|c|c|c|}
\hline Tratamentos & $\begin{array}{c}\text { Comparação entre o percentual médio } \\
\text { de contração da ferida }\end{array}$ & Valor-p \\
\hline (A2 - B1) & $(80,93-54,18)$ & 0,001109 \\
\hline (A2 - A1) & $(80,93-50,55)$ & 0,000408 \\
\hline (A3 - A2) & $(62,54-80,93)$ & 0,02562 \\
\hline (A4 - A2) & $(59,96-80,93)$ & 0,00934 \\
\hline (B2 - B1) & $(78,50-54,18)$ & 0,002614 \\
\hline (B2 - A1) & $(78,50-50,55)$ & 0,000761 \\
\hline (B2 -A4) & $(78,50-59,96)$ & 0,0242 \\
\hline (B3 - A2) & $(58,79-80,93)$ & 0,005919 \\
\hline (B3 - B2) & $(58,79-78,50)$ & 0,01527 \\
\hline (B4 - A2) & $(55,23-80,93)$ & 0,001578 \\
\hline (B4 - B2) & $(55,23-78,50)$ & 0,003851 \\
\hline
\end{tabular}

No que se refere aos subgrupos utilizados no experimento, independentemente de ter sido aplicado buscando um efeito protetor (A) ou curativo (B), o subgrupo Chá (A2/ B2) se mostrou com uma média significativamente maior que os demais subgrupos. Isto significa que o tratamento com chá, apresentou uma média percentual de contração da feriada superior a todos os outros subgrupos.

FIGURA 2. Avaliação clinica das feridas aos 7 e 14 dias. (A) Lesão em língua nos ratos dos grupos A1 que receberam água destilada e (B) que não recebeu tratamento (controle) ambos 07 dias após a indução da queimadura. Processo de contração da ferida nos animais do grupo A2 (C) e B2 (D) que obtiveram maior contração da ferida aos 14 dias.
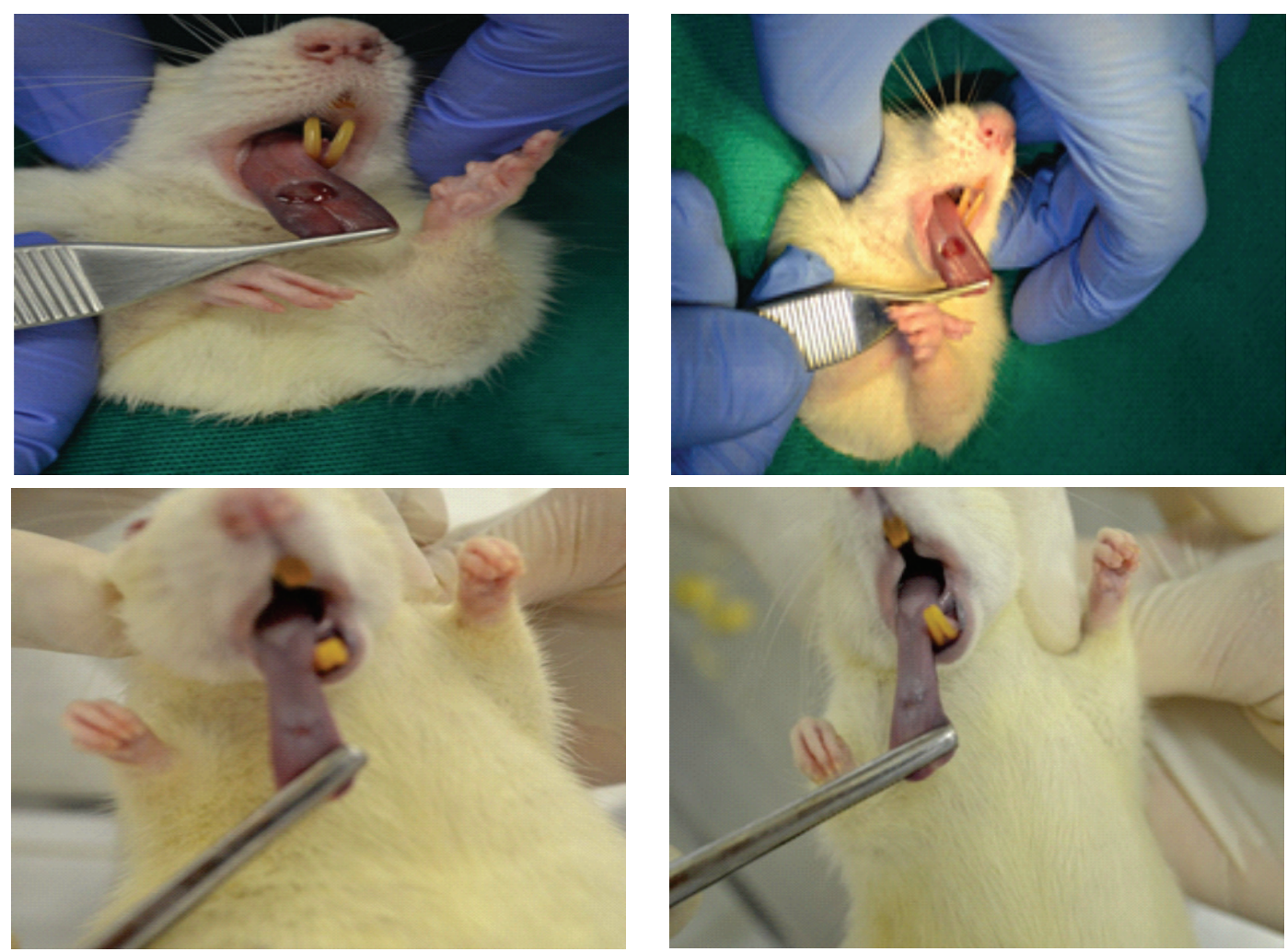


\section{DISCUSS ÃO}

Fenômenos simultâneos ocorrem na tentativa de restaurar a integridade funcional do organismo, dentre elas à cicatrização, caracterizada por uma sequência contínua de respostas teciduais a um trauma, no qual células inflamatórias, epiteliais, endoteliais, plaquetas e fibroblastos se juntam brevemente fora de seu meio normal, interagem e restauram a arquitetura tecidual normal, feito isto volta a sua função normal ${ }^{23}$.

Neste estudo, buscou-se avaliar os efeito protetor (Grupo A) e curativo (Grupo B) da Punica granatum L, utilizando sua apresentação em chá e suco, usados separadamente e/ou associados, no processo de proteção da mucosa e cicatrização de feridas na cavidade oral de ratos. A análise dos fitoconstituintes das amostras preparadas do suco da polpa mostrou a presença de flavonoides e taninos. No chá do fruto desidratado da Punica granatum L. encontrou-se alcaloides, flavonoides, taninos, proteínas, aminoácidos e carboidratos. Este achados corroboram com os estudos de Pereira ${ }^{24}$ (2015), no qual se refere a Punica granatum L. como uma planta com grande potencial de uso na prevenção e tratamento de vários tipos de câncer, infecções, doenças inflamatórias, cardiovasculares, diabetes e outras doenças. Sendo o fruto, a parte do vegetal mais estudada e que contém diferentes compostos dos quais se destacam os taninos e flavonoides.

Durante a avaliação dos achados encontrados, observou-se que os subgrupos: A1 que fez uso da água destilada e o B1, que não recebeu tratamento, apresentaram o menor índice de contração da ferida quando comparados com os resultados dos demais tratamentos utilizados no experimento aos 7 e 14 dias. Em contrapartida, o grupo protetor (Grupo A), no qual o uso do fitoterápico iniciou 07 dias antes da realização da ferida, teve o seu subgrupo A2, que aplicou localmente o chá, com um nível de contração da ferida maior aos demais subgrupos. Já aos 14 dias, houve progressão da contração da ferida com uma média de 80,93\%, seguida pelo A3 (chá + suco) 62,55\%, A4 (suco) 59,97\%. Porem clinicamente não houve a cicatrização completa das feridas, o que contrasta com os achados de Murthy et al. ${ }^{11}$ (2004) que avaliaram o tempo de resolução de feridas em pele de ratos Wistar, que receberam aplicações de gel da casca da romã a 5\% e 2,5\%, no qual apresentaram uma cicatrização completa aos 10 e 12 dias respectivamente. O que nos leva a pensar que a cicratização incompleta das feridas em nosso estudo, talvez tenha relação com vários fatores tais como: localização, umidade, trauma alimentar e a microbiota oral presente.

Estudos de Al-olayan ${ }^{25}$ et al. (2014), mostram que o efeito protetor da romã pode ser devido tanto ao aumento da atividade do sistema de defesa antioxidante quanto à inibição da peroxidação lipídica e da produção de óxido nítrico, o que não foi possível avaliar em nosso estudo devido a metodologia aplicada. Além disso, os efeitos farmacológicos de flavanóides estão relacionados com a sua atividade antioxidante, que pode ser devido à sua capacidade de sequestrar $\mathrm{OH}-\mathrm{e} \mathrm{O} 2$, para exercer um efeito sinérgico com outros metabolitos antioxidantes ${ }^{25}$.

No que diz respeito aos achados referente ao grupo curativo (Grupo B), que recebeu o fitoterápico imediatamente após a realização da queimadura, a análise da contração das feridas aos 7 dias foi observado que todos os subgrupos apresentaram resultados equivalentes. Quando realizada a avaliação aos 14 dias, observou-se que B2, fez uso do chá apresentou $78,50 \%$ de contração da ferida, B3 que fez uso do chá + suco, apresentou 58,79\%, seguido B4, 
que fez uso do suco, com 55,23\%. Esses dados contrastam com os resultados encontrados no estudo de Nascimento Junior ${ }^{21}$ (2016), onde avaliou a cicatrização em língua de ratos e observou que o uso sinérgico do chá da casca associado ao suco da romã foi o que obteve melhor resposta aos 14 dias. Este fato pode estar relacionado à forma de utilização do suco, onde no estudo ${ }^{21}$ o suco foi liofilizado previamente à utilização enquanto que em nosso estudo o mesmo foi utilizado de forma in natura. É provável que os princípios ativos do suco liofilizado, mesmo administrado sistemicamente, cheguem em maior quantidade no local da ferida influenciando de forma significativa no processo de cicatrização.

Quando comparado os grupos protetor (Grupo A) e curativo (Grupo B) observou-se que aos 07 dias, apenas o subgrupo A2, que fez uso do chá aplicado localmente, obteve contração clinicamente satisfatória em relação aos demais. Estes resultados corroboram com os estudos de Manasathien ${ }^{26}$ et al. (2011) onde relatam que o pré-tratamento tópico no dorso de ratas com o extrato da casca da romã reduziu o eritema, o espessamento epidérmico e a fragmentação do DNA. Já aos 14 dias, se mostraram mais eficaz no tratamento os subgrupos A2 e B2, ambos fizeram uso do chá aplicado localmente. Segundo, McCarrell ${ }^{27}$ et al. (2008) e Gümüşs ${ }^{28}$ et al. (2013) a ação cicatricial do chá de romã está também associado à ação antifúngica e antibactericida dessa punicácea, que diminui a população de bactérias Gram positivas e Gram negativas do biofilme dental, diminuindo, assim, a translocação bacteriana para camada mais internas da mucosa. De acordo com Monteiro ${ }^{29}$ et al. (2005). O extrato de Punica granatum L. é rico em taninos e outros compostos fenólicos. Em processos de cura de feridas, queimaduras e inflamações, os taninos auxiliam formando uma camada protetora (complexo tanino-proteína e/ou polissacarídeo) sobre tecidos epiteliais lesionados, podendo, o processo curativo ocorrer naturalmente.

Quando comparado os subgrupos A2 e B2 com relação ao tipo de tratamento mais eficaz, se protetor ou o curativo, não houve resultado estatisticamente significativo em nosso estudo. No entanto, clinicamente observou-se resultados mais favoráveis para o grupo protetor, ou seja, a Punica granatum L quando utilizada previamente a realização da ferida, supostamente a cicatrização se deu em menor período de tempo.

\section{CONCLUSÃO}

Os resultados obtidos sugerem que os tratamento protetor (Grupo A) e curativo (Grupo B) utilizando o fitoterápico na forma de chá, A2 e B2, apresentou clinicamente e estatisticamente uma média percentual de contração da feriada superior a todos os outros tratamentos. Entretanto, novos estudos são necessários para melhor elucidação desses achados. 


\section{REFERÊNCIAS}

1. Altuner EM. Investigation of antimicrobial activity of Punica granatum L . fruit peel ash used for protection against skin infections as folk remedies especially after male circumcision. African J Microbiol Res. 2011; 5(20):3339-42.

2. Reddy MK, Gupta SK, Jacob MR, Khan SI, Ferreira D. Antioxidant, antimalarial and antimicrobial activities of tannin-rich fractions, ellagitannins and phenolic acids from Punica granatum L. Planta Med. 2007;73(5):461-7. 3. Lansky EP, Newman RA. Punica granatum (pomegranate) and its potential for prevention and treatment of inflammation and cancer. J Ethnopharmacol. 2007; 109(2):177-206.

4. Gullon B, Pintado ME, Perez-Alvarez JA, Viuda-Martos M. Assessment of polyphenolic profile and antibacterial activity of pomegranate peel (Punica granatum) flour obtained from co-product of juice extraction. Food Control. 2016; 59:94-98.

5. Aguilera-Carbo A, Augur C, Prado-Barragan LA, Favela-Torres E, Aguilar CN. Microbial production of ellagic acid and biodegradation of ellagitannins. Appl Microbiol Biotechnol. 2008;78(2):189-99.

6. Endo EH, Cortez DAG, Ueda-Nakamura T, Nakamura CV, Dias Filho BP. Potent antifungal activity of extracts and pure compound isolated from pomegranate peels and synergism with fluconazole against Candida albicans. Res Microbiol. 2010;161(7):534-40.

7. Faria A, Calhau C. The bioactivity of pomegranate: impact on health and disease. Crit Rev Food Sci Nutr. 2011;51:626-634.

8. CHINSEMBU KC. Plants and other natural products used in the management of oral infections and improvement of oral health. Acta Trop. 2016;154:6-18.

9. Gul F, Shinwari ZK, Afzal I. Screening of indigenous knowledge of herbal remedies for skin diseases among local communities of North West Punjab, Pakistan. Pak J Bot. 2012;44(5):1609-16.

10. Moneim AEA. Antioxidant activities of Punica granatum (pomegranate) peel extract on brain of rats. J Med Plant Res. 2012; 6(2);195-199.

11. Murthy KNC, Reddy VK, Veigas JM, Murthy UD. Study on Wound Healing Activity of Punica granatum Peel. J Med Food. 2004;7(2):256-259.

12. Pirbalouti AG, Azizi S, Koohpayeh A, Hamedi B. Wound Healing Activity of Malva Sylvestris and Punica Granatum in Alloxan-Induced Diabetic Rats. Acta Pol Pharm [periódico online]. 2010; 67(5):511-16 Disponível em URL: http://ptfarm.pl/pub/File/Acta_Poloniae/2010/5/511.pdf

13. Husari A, Khayat A, Bitar H, Hashem Y, Rizkallah A, Zaatari G, et al. Antioxidant activity of pomegranate juice reduces acute lung injury secondary to hyperoxia in an animal model. BMC Res Notes. 2014; 7(664):1-10. 14. Hello M, Barbarot S, Bastuji-Garin S, Revuz J, Chosidow O. Use of thalidomide for severe recurrent aphthous stomatitis: a multicenter cohort analysis. Medicine (Baltimore). 2010; 89(3):176-82.

15. Messadi DV, Younai F. Aphthous ulcers. Dermatol Ther. 2010 May-Jun; 23(3):281-90.

16. Costa, GBF, Castro JFL. Etiologia e tratamento da estomatite aftosa recorrente - revisão de literatura, Medicina (Ribeirão Preto). 2013; 46(1):1-7.

17. Hespanhol FL, Tinoco EMB, Castro HG, Falabella MEV, Assis NMSP. Manifestações Bucais em Pacientes Submetidos a quimioterapia. Ciênc. Saúde Colet. 2010; 15 Suppl.1:1085-1094.

18. Teles DG, Costa, MM. Estudo da ação antimicrobiana conjunta de extratos aquosos de Tansagem (Plantago major l., Plantaginaceae) e Romã (Punica granatum L., Punicaceae) e interferência dos mesmos na ação da amoxicilina in vitro. Rev. bras. plantas med. 2014; 16(2):323-328.

19. Bhandary SR, Kumari NS, Brat VS, Sharmila RP, Bekal, PM. Preliminary Phytochemical Screening Of Various Extracts Of Punica Granatum Peel, Whole Fruit And Seeds. NUJHS. 2012 Dec; 2(4): 34-38.

20. Mohan M, Waghulde H, Kasture S. Effect of pomegranate juice on Angiotensin II-induced hypertension in diabetic Wistar rats. Phytother Res. 2010 Jun;24 Suppl 2:S 196-203.

21. Nascimento Júnior BJ, Santos AMT, Souza AT, Santos EO, Xavier MR, Mendes RL et al. Pomegranate action study (Punica granatum L.) for the healing of ulcers induced by burns to the dorso-lingual mucosa in Wistar rats (Rattus norvegicus). Rev. Bras. Pl. Med,Campinas. 2016;18(2):423-432.

22. Teo TC, Naylor IL. Modifications to the rate of wound contraction by olloopurinal. Br J Plast Surg 1995; 48(4):198-202.

23. Galvão CBC, Pessoa DCNP, Pinheiro ALB. A comparative study on the healing of oral wounds in animals fed with DBR and supplemented diet. Rev Bras Med. 2000; 57(8): 844-850.

24. Pereira ST. Obtenção e caracterização do extrato seco por spray drying de Punica granatum para o desenvolvimento de comprimidos mucoadesivos. [Dissertação de Mestrado]. Teresina: Universidade Federal do Piauí - UFPI, 2015. 
25. Al-Olayan EM, El-Khadragy MF, Metwally DM, Abdel Moneim AE. Protective effects of pomegranate (Punica granatum) juice on testes against carbon tetrachloride intoxication in rats. BMC Complement Altern Med. 2014;14 (164): 1472-6882.

26. Manasathien J, Kupittayanant S, Indrapichate K. Protective efficacy of pomegranate (Punica granatum Linn., Punicaceae) peel ethanolic extracts on UVB-irradiated rat skin. American-Eurasian Journal of Toxicology Sciences 2011; 4(3):250-258.

27. McCarrell EM, Gould SWJ, Fielder MD, Kelly AF, Sankary WE, Naughton DP. Antimicrobial activities of pomegranate rind extracts: enhancement by addition of metal salts and vitamin C. BMC Complement Altern Med. 2008; 15(64): 1-7.

28. Gümüş M, Tekin R, Firat U, Önder A, Kapan A, Böyük A et al. The effects of pomegranate on bacterial translocation in rats with obstructive jaundice. Eur Rev Med Pharmacol Sci. 2013; 17:1488-1494.

29. Monteiro JM, Albuquerque UP, Araújo EL. Taninos: Uma abordagem da química à ecologia. Qim. Nova. 2005;28(5):892-896. 